\title{
FDG-PET and PET/CT in Breast Cancer Staging
}

\author{
Norbert Avril ${ }^{a, c}$ Stephen J Mather ${ }^{a, c}$ Rebecca Roylance ${ }^{b, c}$ \\ a Department of Nuclear Medicine, \\ ${ }^{b}$ Department of Medical Oncology, Barts and The London NHS Trust, \\ ${ }^{\mathrm{c}}$ Institute of Cancer, Molecular Oncology and Imaging, Queen Mary, University of London, UK
}

Key Words

F-18 FDG · PET/CT · Breast cancer · Imaging · Staging · Follow-up

\section{Summary}

Positron emission tomography (PET) using the glucose analogue F-18 fluorodeoxyglucose (FDG) enables the visualisation of increased glucose metabolism in cancer. Whole-body FDG-PET can be used for staging patients with breast cancer to identify metastatic disease. The metabolic information from FDG-PET is more sensitive than conventional structural imaging for the detection of loco-regional and distant metastases. FDG-PET is superior in detecting tumour-involved lymph nodes, particularly those which are normal in size radiologically and is superior in characterising enlarged lymph nodes as positive or negative. The overall sensitivity for bone scintigraphy and FDG-PET have been reported as comparable, but bone scintigraphy seems to be superior in the detection of osteoblastic disease and FDG-PET in osteolytic metastases, suggesting a complementary role for both imaging procedures. Due to its ability to more accurately stage patients with locally advanced breast cancer, FDG-PET may have a significant impact on patient management especially in combination with computed tomography (CT). Combined FDG-PET/CT provides both metabolic information from FDG-PET and the anatomical information from CT. FDG-PET/CT could potentially replace currently used imaging modalities and consolidate the diagnostic work-up of breast cancer patients with locally advanced or suspected locally recurrent or metastatic disease.

\author{
Schlüsselwörter \\ F-18 FDG · PET/CT · Mammakarzinom • Bildgebung · \\ Staging · Follow-up
}

\section{Zusammenfassung}

Die Positronen-Emissions-Tomographie (PET) mit Fluor18-Fluordeoxyglukose (FDG) stellt den verstärkten Glukosestoffwechsel maligne entarteter Zellen dar. Ganzkörper-FDG-PET kann bei Brustkrebspatientinnen sowohl zum Staging als auch zum Nachweis von Metastasen eingesetzt werden. Durch FDG-PET gewonnene metabolische Informationen sind oft sensitiver im Erkennen von lokoregionalen und Fernmetastasen als anatomische bildgebende Verfahren. FDG-PET ist überlegen beim Nachweis von infiltrierten Lymphknoten - insbesondere von radiologisch unauffälligen - sowie beim Einstufen vergrößerter Lymphknoten als positiv oder negativ. Generell wird die Sensitivität von Knochenszintigraphie und FDG-PET als gleichwertig eingestuft. Osteolytische Metastasen werden in der Regel jedoch besser mit FDG-PET und osteoblastische Metastasen besser mit der Knochenszintigraphie diagnostiziert, was auf eine potentiell komplementäre Rolle beider Verfahren hindeutet. Auf Grund des präziseren Stagings von Patientinnen mit lokal fortgeschrittenen Mammakarzinomen könnte FDGPET eine wichtige Rolle beim Patientenmanagement spielen, insbesondere in der Kombination FDG-PET/ Computertomographie (CT). FDG-PET/CT liefert sowohl metabolische (FDG-PET) als auch anatomische Information (CT). FDG-PET/CT könnte in Zukunft bisher eingesetzte Bildgebungsverfahren ersetzen sowie die Diagnostik von Brustkrebspatientinnen mit lokal fortgeschrittener Erkrankung bzw. vermuteten Lokal- oder Fernmetastasen vereinigen.

\begin{tabular}{|c|c|}
\hline KARGER & (C) 2007 S. Karger GmbH, Freiburg \\
\hline $\begin{array}{l}\text { Fax +49 } 7614520714 \\
\text { E-mail Information@Karger.de } \\
\text { www.karger.com }\end{array}$ & $\begin{array}{l}\text { Accessible online at: } \\
\text { www.karger.com/brc }\end{array}$ \\
\hline
\end{tabular}

Norbert Avril, M.D.

Department of Nuclear Medicine, Barts and The London, Queen Mary University of London

West Smithfield (QE II), London EC1A 7BE, United Kingdom Tel. +44 20 7601-7144, Fax -7149

E-mail n.e.avril@qmul.ac.uk 


\section{Positron Emission Tomography}

Positron emission tomography (PET) is a functional imaging technology which enables the visualisation, characterisation and quantification of biological processes in vivo. By using positron emitting radiotracers, PET provides unique information about the molecular and metabolic changes associated with disease (molecular imaging). PET measures the distribution of radiotracers in the body and converts the data into cross-sectional images. Dedicated PET scanners have been developed and refined over the past 2 decades which now enable rapid, reliable and reproducible imaging in humans. PET is highly sensitive, with the capacity to detect subnanomolar concentrations of radiotracer, and provides superior image resolution to conventional gamma camera imaging.

The accomplishments of PET in oncology can be primarily attributed to the fact that depending on the radiolabelled tracer used, PET can visualise various biological processes in tumours, such as glucose metabolism, cell proliferation, perfusion and hypoxia. Glucose metabolism is often increased in malignant tumours resulting in increased cellular uptake of the glucose analogue F-18 fluorodeoxyglucose (FDG) (fig. 1). Imaging the metabolic activity of tumours provides both more sensitive and specific information about the extent of disease compared with anatomical imaging alone [1]. FDG-PET has become a standard imaging procedure for staging many types of cancer and, in the USA, insurance coverage currently includes head and neck, thyroid, lung, breast, oesophageal and colorectal cancers, lymphoma, melanoma and solitary pulmonary nodules. In February 2006, the Centers for Medicare and Medicaid Services (CMS) announced that it would provide coverage for use of FDG-PET in essentially all other cancers in accordance with its 'coverage with evidence development' program.

Combined PET and computed tomography (PET/CT) is a new imaging technology which has recently become available. Combined PET/CT devices acquire PET and CT images that are concurrent and co-registered, merging the functional information from PET with the anatomical information from CT [2]. An important limitation of FDG-PET alone is the precise localisation of abnormalities due to the lack of reliable anatomical landmarks and the limited spatial resolution of current PET scanner technologies. PET/CT is unique because it provides tissue characterisation as well as assessment of the exact localisation and the extent of tumour tissue. The use of FDG-PET/CT has been shown to improve the diagnostic accuracy compared to either imaging procedure alone by localising areas of increased FDG uptake with improved anatomic specificity and by providing better characterisation of suspicious morphological abnormalities [3] (figs. 2, 3).

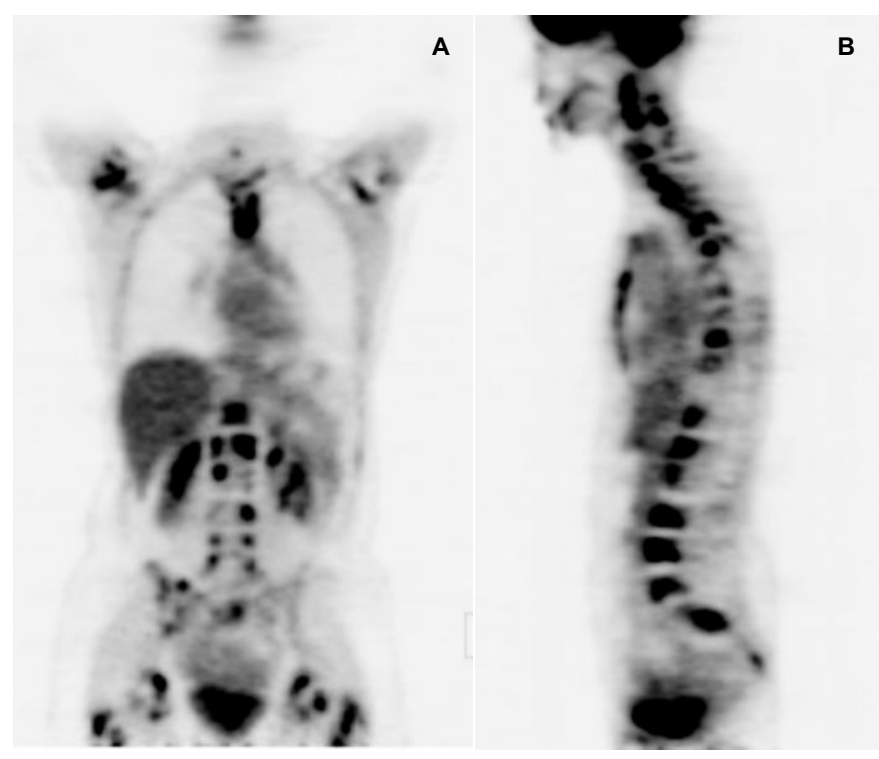

Fig. 1. Patient with multiple areas of increased FDG uptake on PET which correspond to bony metastases as seen on $\mathbf{A}$ a coronal and $\mathbf{B}$ a sagittal slice.

\section{FDG-PET Procedures and Image Analysis}

To ensure a standardised metabolic state, especially low plasma glucose and insulin levels, it is necessary that patients for oncologic PET imaging have fasted for at least $4-6 \mathrm{~h}$ prior to administration of FDG. The blood glucose level should be tested prior to tracer injection and should not exceed $8.5 \mathrm{mmol} / \mathrm{l}(150 \mathrm{mg} / 100 \mathrm{ml})$ [4]. Most FDG is taken up by tissue within $1 \mathrm{~h}$ after tracer injection, and PET data acquisition is initiated after approximately $60 \mathrm{~min}$. Some studies found increasing target-to-background ratios over time suggesting benefits to longer waiting periods between tracer injection and data acquisition [5]. However, lower image quality, due to radionuclide decay, has to be taken into account.

Correction for photon attenuation is required for quantification of tissue tracer uptake, which can be obtained by using radioactive sources which are rotating around the patient or by co-registered CT data. Calculating standardised uptake values (SUVs) by normalisation of tissue FDG uptake to injected activity and body weight is the most common method for tumour quantification [6]. Quantification of tumour tracer uptake allows for comparison between PET studies performed in the same patient at different times but also among different patients. Although SUVs have been shown to be important for monitoring treatment effects, visual image analysis is generally sufficient for staging and re-staging purposes.

Visual PET interpretation should include analysis of transaxial, coronal and sagittal views. Cancer typically presents with focally increased FDG uptake, whereas most benign tumours are negative in FDG-PET. Increased FDG uptake or retention is found within the brain cortex, the myocardium and the urinary tract. Low to moderate uptake is often seen in the 


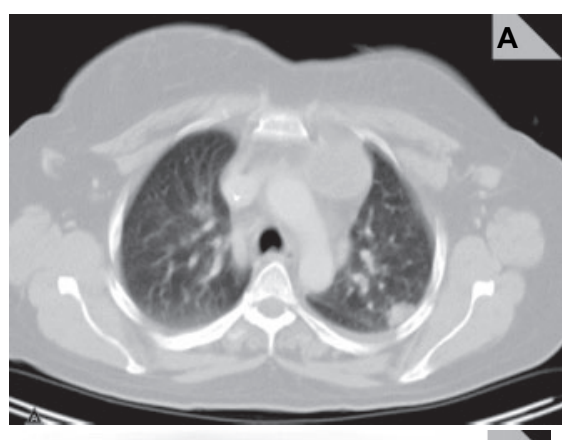

B

Fig. 2. A Breast cancer patient with lung metastases identified on CT. B FDG-PET identifies additional lymph node involvement in the left axilla. C This is clearly visualized on co-registered FDG-PET/CT.

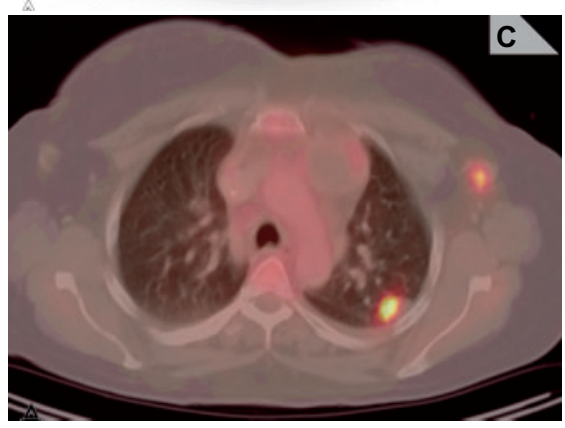

base of the tongue, the salivary glands, thyroid, liver, spleen, gastrointestinal tract, bone marrow, musculature and reproductive organs. There are inherent limitations of FDG-PET that can result in an increase of false-negative as well as falsepositive findings. The most common normal cause of misinterpretation is related to muscle activity. Muscle tension may lead to increased FDG uptake and physical activity immediately before or after tracer injection can lead to spurious muscle activity. False-positive findings are most commonly associated with uptake of FDG in infectious or inflammatory tissue. In different situations FDG-PET can actually be helpful in imaging infections by visualising the increased metabolic activity of activated granulocytes and mononuclear cells. Another cause of false-positive results is related to treatment. FDG uptake can be seen in tissue after radiation therapy and it is therefore recommended to wait at least 8 weeks after external beam radiation to evaluate the irradiated area for residual disease [7]. For chemotherapy, a waiting period of at least 4 weeks after the last cycle is recommended to avoid falsenegative PET results due to metabolic stunning of tumour tissue [8]. In addition, the bone marrow frequently exhibits increased metabolic activity following chemotherapy, which makes it more difficult to identify bone metastases. False-positive findings can occur in benign conditions such as Paget's
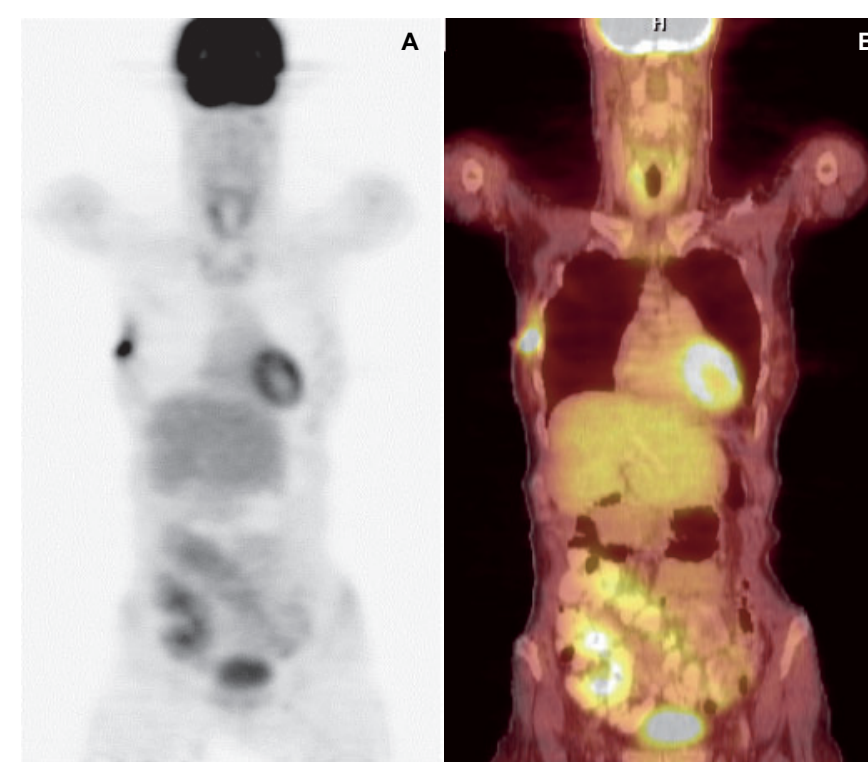

Fig. 3. A Recurrent breast cancer in the right breast on coronal FDGPET, B co-registered FDG-PET/CT.

and Graves' disease, thyroid, adrenal and villous adenomas, healing fractures, and a few benign tumours. Other pitfalls include increased FDG uptake in normal ovaries, e.g. during ovulation, as well as normal physiologic activity in bowel, endometrium, and blood vessels and focal retained activity in ureters, bladder diverticula and pelvic kidneys [9]. Wholebody imaging can be improved by intravenous injection of furosemide $(20-40 \mathrm{mg})$ to reduce tracer retention in the urinary system and by n-butyl-scopolamine (20-40 mg) to reduce FDG uptake in the bowel [10]. Weaknesses of FDG-PET for cancer imaging include its limited spatial resolution of 4-8 mm currently achievable in commercial systems. It is important to note that a negative FDG-PET scan cannot exclude the presence of small tumour deposits or microscopic tissue involvement.

\section{FDG-PET for Staging/Assessment of Metastatic Disease}

Distant metastases of breast cancer are frequently found in lymph nodes, lungs, liver and bones. Therefore, chest X-ray and abdominal ultrasound and/or CT scans, and bone scintigraphy are routinely performed both for initial staging and assessment of locally recurrent or metastatic disease. Additionally magnetic resonance imaging (MRI) can be used for further evaluation of suspicious findings.

Most data using FDG-PET comes from the assessment of patients with suspected recurrent and/or metastatic disease compared to conventional imaging [11-17]. Although some studies have included follow up of asymptomatic patients [15, 17]. A recent meta-analysis on the diagnostic performance of FDGPET in this setting from Isasi and colleagues [18] included 
18 articles published from January 1995 to June 2004. Among the studies with patient-based data, the median sensitivity was $92.7 \%$, and the median specificity was $81.6 \%$. The pooled sensitivity was $90 \%$ and the pooled false-positive rate was $11 \%$ after the exclusion of outliers. The maximum joint sensitivity and specificity was $88 \%$. This led the authors to conclude that FDG-PET was a valuable tool in the management of these patients. Indeed in a number of studies using FDG-PET to assess metastatic disease, treatment of the patient has been altered as a consequence [16]. 125 patients were assessed with both FDG-PET and conventional imaging. FDG-PET findings were confirmed by histopathology or follow-up imaging, and the reviewers were blinded to outcome. FDG-PET increased the extent of disease in 54 (43\%) patients, and decreased the extent of disease in $30(24 \%)$ of 125 patients. As a result, the therapeutic plan was altered in $40(32 \%)$ patients, and supported the therapeutic plan in $34(27 \%)$ patients. It was unchanged in the remaining 51 (41\%) patients.

There are much less data using FDG-PET as part of the initial diagnostic work-up to assess the presence of metastatic disease. However, the data again suggest its superiority to conventional imaging. FDG-PET was performed if chest X-ray, bone scan, liver ultrasound or CT did not reveal distant metastases in patients with locally advanced disease planned for neoadjuvant chemotherapy [19]. Among the 48 patients evaluated with FDG-PET, 14 had abnormal FDG uptake, and metastases were suspected in 12 patients. Further assessment was done, either with further imaging or biopsy where feasible, and 4 sites were confirmed to be metastases, which led to a change in management, with 10 sites remaining abnormal. Thus, while useful, the authors recommended that abnormal FDG-PET findings should be confirmed to prevent patients from being denied appropriate treatment. However, equally the upstaging of $8 \%$ of patients did mean that those patients were spared unnecessary aggressive treatment which would not alter their overall prognosis.

Another study examined the role of FDG-PET in determining the extent of disease in high-risk, operable breast cancer compared with CT and bone scintigraphy in 80 patients [20]. Imaging findings were verified by biopsy or long-term follow-up. 10 patients had distant metastases seen on both conventional imaging and FDG-PET, and 4 patients had additional metastases on FDG-PET, an upstaging of $5 \%$. Importantly, the specificity was significantly higher for FDG-PET compared to $\mathrm{CT}$ and bone scintigraphy, thus, suggesting that this may be a valuable modality to add to the staging investigations in highrisk operable patients.

A specific clinical scenario where FDG-PET has been evaluated is in the diagnosis of brachial plexopathy which is difficult to assess on conventional anatomical imaging. FDG-PET and MRI were performed in 10 patients with clinical findings suggestive of breast cancer metastases [21]. Out of 9 patients who had loco-regional metastases, MRI was positive in 5 patients and indeterminate in 4 patients, whereas FDG-PET was posi- tive in all patients. Similar results were found by Ahmad et al. [22] in 19 breast cancer patients with symptoms referable to the brachial plexus. These studies suggest that MR or CT imaging and FDG-PET are complementary in detecting and characterising brachial plexopathy, especially if other imaging studies are normal. FDG-PET may be particularly useful in distinguishing between radiation-induced and metastatic plexopathy.

\section{FDG-PET/CT in Staging and Assessment of Metastatic Disease}

There is even more limited data regarding the use of FDGPET/CT for the evaluation of patients with breast cancer [23, 24]. In a retrospective review of 75 patients, FDG-PET/CT was compared with FDG-PET and CT [24]. In the case of discordant findings, comparison with histological or follow-up results was made. FDG-PET/CT added incremental diagnostic confidence to FDG-PET in more than $50 \%$ of patients with increased FDG uptake. FDG-PET/CT also detected more regions with tumour recurrence than CT. Another study also comparing FDG-PET/CT utilising a low-dose CT with a contrast enhanced $\mathrm{CT}$ of selected body regions, both performed on the same day showed an improvement in FDG-PET/CT compared to CT alone [25]. 49 patients underwent 70 imaging procedures; 17 for initial staging and 53 for restaging. 210 out of 257 lesions were concordant between PET/CT and the contrast enhanced CT; 47 were discordant and verified by either biopsy $(n=35)$ or follow-up. FDG-PET/CT correctly identified 25 true-positive lesions and incorrectly found 2 false-positive lesions, while contrast enhanced CT incorrectly identified 18 false-positive lesions. The sensitivity, specificity and accuracy for FDG-PET/CT were 97.8, 93.5 and 97.3\%, and for contrast enhanced CT 87.6, 42 and $82.1 \%$, respectively.

A study examining 46 consecutive breast cancer patients with elevated serum tumour markers during follow-up found tumour recurrences in 30 [26]. 31 patients had abnormal FDGPET/CT studies with an overall sensitivity, specificity and accuracy of 90,71 and $83 \%$, respectively. In 37 patients, FDG$\mathrm{PET} / \mathrm{CT}$ was compared with contrast-enhanced CT and provided a higher sensitivity ( 85 vs. $70 \%$ ), specificity (76 vs. $47 \%$ ) and accuracy ( 81 vs. $59 \%$ ). Overall, FDG-PET/CT had an impact on management in $51 \%$ of patients. This included commencing chemotherapy or radiotherapy.

However, another study found that FDG-PET/CT only marginally improved the accuracy over FDG-PET alone in breast cancer patients [27]. FDG-PET staged 79.3\% (46/58) of the patients correctly, overstaged $7(12.1 \%)$, and understaged 5 patients $(8.6 \%)$. Integrated FDG-PET/CT staged $89.7 \%$ $(52 / 58)$ of the patients correctly, overstaged $4(6.9 \%)$, and understaged 2 patients $(3.4 \%)$. Thus, the staging accuracy of FDG-PET/CT was not significantly better than that of FDGPET alone. Lesions exhibiting mild hypermetabolic activity, 
benign inflammatory lesions and physiological variants largely explained the incorrect FDG-PET findings.

\section{FDG-PET and PET/CT for Detection of Bone Metastases}

The skeleton is a common site for distant metastases in breast cancer. Bone scintigraphy is used for screening of bony metastases and allows the extent of disease to be determined. However, tracer uptake in bone scintigraphy reflects osteoblastic activity and is therefore limited in the detection of osteolytic lesions and metastases confined to the marrow cavity. Studies using FDG-PET compared to bone scintigraphy have found FDG-PET better at detecting osteolytic lesions, whereas bone scintigraphy is better for osteoblastic lesions [28-31]. These studies have shown sensitivity, specificity and accuracy of FDG-PET to be 77.7-95.2, 88.2-97.6 and 83.1-94.5\% and for bone scintigraphy to be $77.7-93.3,80.9-82.4$ and $78.7-80.3 \%$, respectively. In another study, the visualisation rate of bone scintigraphy compared to FDG-PET was examined looking at 4 different types of bone metastases as classified on the basis of multi-slice CT. This found that bone scintigraphy compared to FDG-PET identified 100 vs. $55.6 \%$ for the osteoblastic type, 70.0 vs. $100.0 \%$ for the osteolytic type, 84.2 vs. $94.7 \%$ for the mixed type and 25.0 vs. $87.5 \%$ for the invisible type [29]. It would therefore appear that FDG-PET and bone scintigraphy should be used in a complementary manner in detecting bony metastases in breast cancer.

A distinct advantage of FDG-PET is the ability to assess tumour viability following previous treatments. Bony metastases are particularly difficult to evaluate since radiological appearances often persist despite successful treatment. FDG$\mathrm{PET} / \mathrm{CT}$ might be advantageous in this situation as it allows definition of the metabolic activity of lesions seen on CT. A recent study followed 146 bone metastases in 25 patients with recurrent breast cancer identified by FDG-PET/CT [32]. The majority of the osteolytic (93.5\%) and mixed-pattern lesions $(81.8 \%)$, but fewer of the osteoblastic lesions (61\%), showed increased FDG uptake. After treatment, 58 osteolytic lesions (80.5\%) became FDG-negative and osteoblastic on CT with only 14 relatively large lesions $(19.5 \%)$ remaining FDG-avid. Of the 25 FDG-avid osteoblastic lesions, 13 (52\%) became FDG-negative, but 12 (48\%) remained FDG-avid and increased in size on CT. 5 of the mixed-pattern lesions remained FDG-avid after treatment. All 17 CT-negative lesions became FDG-negative; however, 9 of them became osteoblastic. None of the initially FDG-negative lesions showed FDG avidity during follow-up. From this study it is likely that FDG uptake reflects the immediate tumour activity of bone metastases, whereas the radiographic morphology changes vary greatly with time among patients. Thus, FDG-PET/CT maybe very useful in monitoring treatment response in bones especially in the context of clinical trials and for those patients with boneonly metastatic disease.

\section{Conclusion}

A distinct advantage of FDG-PET in patients with breast cancer is the ability to provide accurate diagnostic information as a whole-body imaging modality. In general, the metabolic information from FDG-PET is more sensitive than conventional imaging for the detection of distant metastases. Although still used in many centres, plain chest X-ray is insufficient for detection of early lung metastases compared to FDG-PET, CT or combined FDG-PET/CT. Bone scintigraphy is a sensitive test to detect bone metastases but it lacks specificity and frequently abnormal findings require further imaging studies. Although the overall sensitivity for bone scintigraphy and FDG-PET are reported as comparable, bone scintigraphy seems to be superior in the detection of osteoblastic disease whereas FDG-PET is superior for osteolytic metastases, suggesting a complementary role for both imaging procedures. Although the overall diagnostic performance of CT and FDG-PET are similar, these imaging modalities also appear to be complementary. FDG-PET is superior in detecting tumour-involved lymph nodes, particularly those which are normal in size radiologically and is superior in characterising enlarged lymph nodes as positive or negative. CT is clearly superior in detecting small lung metastases with a size of a few millimetres. For larger lung masses, the metabolic information from FDG-PET provides superior specificity, enabling a more accurate characterisation. The diagnostic accuracy of FDG-PET and CT for liver metastases is similar but the results are often complementary as FDG-PET provides a higher specificity.

There would therefore seem to be a potential role for FDG$\mathrm{PET} / \mathrm{CT}$ in specific clinical scenarios, which are worth investigating further. Firstly, for the staging of women who present with locally advanced breast cancer. If more accurate staging of these women was possible, it would spare those women who already have metastatic disease from unnecessarily aggressive treatment. Furthermore, it would be very useful to be able to separate out in clinical trials those women that are stage III from those that actually have metastatic disease. Secondly, for the staging of high risk operative breast cancer patients, especially for the identification of lesions of uncertain significance. However, for both these clinical settings FDG-PET/CT does require further evaluation in the context of clinical trials. Thirdly, in the management of brachial plexopathy when trying to establish the cause. Combined FDG$\mathrm{PET} / \mathrm{CT}$ is a promising approach providing both the metabolic information from FDG-PET and the anatomical information from CT. It could potentially replace various currently used imaging modalities and consolidate the diagnostic workup of breast cancer patients with early-stage high-risk operable disease, locally advanced disease and suspected recurrent or metastatic disease. However, further studies are needed to clarify the role of FDG-PET/CT before it can be introduced routinely. 


\section{References}

1 Rohren EM, Turkington TG, Coleman RE: Clinical applications of PET in oncology. Radiology 2004; 231:305-332.

2 Townsend DW, Carney JP, Yap JT, Hall NC: PET/CT today and tomorrow. J Nucl Med 2004;45: 4S-14S.

- 3 Beyer T, Townsend DW, Brun T, Kinahan PE, Charron M, Roddy R, Jerin J, Young J, Byars L, Nutt R: A combined PET/CT scanner for clinical oncology. J Nucl Med 2000;41:1369-1379.

4 Weber WA, Schwaiger M, Avril N: Quantitative assessment of tumor metabolism using FDG-PET imaging. Nucl Med Biol 2000;27:683-687.

$\checkmark 5$ Boerner AR, Weckesser M, Herzog H, Schmitz T, Audretsch W, Nitz U, Bender HG, Mueller-Gaertner HW: Optimal scan time for fluorine-18 fluorodeoxyglucose positron emission tomography in breast cancer. Eur J Nucl Med 1999;26:226-230.

6 Zasadny KR, Wahl RL: Standardized uptake values of normal tissues at PET with 2-[fluorine- 18]fluoro-2-deoxy-D-glucose: variations with body weight and a method for correction. Radiology 1993; 189:847-850.

7 Andrade RS, Heron DE, Degirmenci B, Filho PA, Branstetter BF, Seethala RR, Ferris RL, Avril N: Posttreatment assessment of response using FDG$\mathrm{PET} / \mathrm{CT}$ for patients treated with definitive radiation therapy for head and neck cancers. Int J Radiat Oncol Biol Phys 2006;65:1315-1322.

8 Juweid ME, Stroobants S, Hoekstra OS, Mottaghy FM, Dietlein M, Guermazi A, Wiseman GA Kostakoglu L, Scheidhauer K, Buck A, Naumann R, Spaepen K, Hicks RJ, Weber WA, Reske SN, Schwaiger M, Schwartz LH, Zijlstra JM, Siegel BA, Cheson BD: Use of positron emission tomography for response assessment of lymphoma: consensus of the Imaging Subcommittee of International Harmonization Project in Lymphoma. J Clin Oncol 2007;25:571-578.

$\checkmark$ Short S, Hoskin P, Wong W: Ovulation and increased FDG uptake on PET: potential for a falsepositive result. Clin Nucl Med 2005;30:707.

10 Stahl A, Weber WA, Avril N, Schwaiger M: Effect of N-butylscopolamine on intestinal uptake of fluorine-18-fluorodeoxyglucose in PET imaging of the abdomen. Nuklearmedizin 2000;39:241-245.

11 Bender H, Kirst J, Palmedo H, Schomburg A, Wagner U, Ruhlmann J, Biersack HJ: Value of F-18 fluorodeoxyglucose positron emission tomography in the staging of recurrent breast carcinoma. Anticancer Res 1997:17:1687-1692.

12 Moon DH, Maddahi J, Silverman DH, Glaspy JA, Phelps ME, Hoh CK: Accuracy of whole-body fluorine-18-FDG PET for the detection of recurrent or metastatic breast carcinoma. J Nucl Med 1998; 39:431-435.
Dose J, Bleckmann C, Bachmann S, Bohuslavizki KH, Berger J, Jenicke L, Habermann CR, Janicke F: Comparison of fluorodeoxyglucose positron emission tomography and 'conventional diagnostic procedures' for the detection of distant metastases in breast cancer patients. Nucl Med Commun 2002; 23:857-864.

14 Gallowitsch HJ, Kresnik E, Gasser J, Kumnig G, Igerc I, Mikosch P, Lind P: F-18 fluorodeoxyglucose positron-emission tomography in the diagnosis of tumor recurrence and metastases in the follow-up of patients with breast carcinoma: a comparison to conventional imaging. Invest Radiol 2003;38: 250-256.

15 Siggelkow W, Zimny M, Faridi A, Petzold K, Buell $\mathrm{U}$, Rath W: The value of positron emission tomography in the follow-up for breast cancer. Anticancer Res 2003;23:1859-1867.

16 Eubank WB, Mankoff D, Bhattacharya M, Gralow J, Linden H, Ellis G, Lindsley S, Austin-Seymour M, Livingston R: Impact of FDG PET on defining the extent of disease and on the treatment of patients with recurrent or metastatic breast cancer. AJR Am J Roentgenol 2004;183:479-486.

17 Santiago JF, Gonen M, Yeung H, Macapinlac H, Larson S: A retrospective analysis of the impact of 18F-FDG PET scans on clinical management of 133 breast cancer patients. Q J Nucl Med Mol Imaging 2006;50:61-67.

18 Isasi CR, Moadel RM, Blaufox MD: A meta-analysis of FDG-PET for the evaluation of breast cancer recurrence and metastases. Breast Cancer Res Treat 2005;90:105-112.

19 Van der Hoeven JJ, Krak NC, Hoekstra OS, Comans EF, Boom RP, van Geldere D, Meijer S, van der Wall E, Buter J, Pinedo HM, Teule GJ, Lammertsma AA: 18F-2-fluoro-2-deoxy-d-glucose positron emission tomography in staging of locally advanced breast cancer. J Clin Oncol 2004;22: 1253-1259.

20 Port ER, Yeung H, Gonen M, Liberman L, Caravelli J, Borgen P, Larson S: 18F-2-fluoro-2-deoxyD-glucose positron emission tomography scanning affects surgical management in selected patients with high-risk, operable breast carcinoma. Ann Surg Oncol 2006;13:677-684.

21 Hathaway PB, Mankoff DA, Maravilla KR, AustinSeymour MM, Ellis GK, Gralow JR, Cortese AA, Hayes CE, Moe RE: Value of combined FDG PET and MR imaging in the evaluation of suspected recurrent local-regional breast cancer: preliminary experience. Radiology 1999;210:807-814

22 Ahmad A, Barrington S, Maisey M, Rubens RD: Use of positron emission tomography in evaluation of brachial plexopathy in breast cancer patients. $\mathrm{Br}$ J Cancer 1999;79:478-482.
23 Veit-Haibach P, Antoch G, Beyer T, Stergar H, Schleucher R, Hauth EA, Bockisch A: FDG$\mathrm{PET} / \mathrm{CT}$ in restaging of patients with recurrent breast cancer: possible impact on staging and therapy. Br J Radiol 2007.

24 Tatsumi M, Cohade C, Mourtzikos KA, Fishman EK, Wahl RL: Initial experience with FDG-PET/ $\mathrm{CT}$ in the evaluation of breast cancer. Eur J Nucl Med Mol Imaging 2006;33:254-262.

25 Piperkova E, Raphael B, Altinyay ME, Castellon I, Libes R, Sandella N, Heiba S, Abdel-Dayem H: Impact of PET/CT in comparison with same day contrast enhanced CT in breast cancer management. Clin Nucl Med 2007;32:429-434.

26 Radan L, Ben-Haim S, Bar-Shalom R, Guralnik L, Israel O: The role of FDG-PET/CT in suspected recurrence of breast cancer. Cancer 2006;107: 2545-2551.

27 Fueger BJ, Weber WA, Quon A, Crawford TL, Allen-Auerbach MS, Halpern BS, Ratib O, Phelps ME, Czernin J: Performance of 2-deoxy-2-[F18]fluoro-D-glucose positron emission tomography and integrated PET/CT in restaged breast cancer patients. Mol Imaging Biol 2005;7:369-376.

28 Cook GJ, Houston S, Rubens R, Maisey MN, Fogelman I: Detection of bone metastases in breast cancer by F-18 FDG PET: differing metabolic activity in osteoblastic and osteolytic lesions. J Clin Oncol 1998;16:3375-3379.

29 Nakai T, Okuyama C, Kubota T, Yamada K, Ushijima Y, Taniike K, Suzuki T, Nishimura T: Pitfalls of FDG-PET for the diagnosis of osteoblastic bone metastases in patients with breast cancer. Eur J Nucl Med Mol Imaging 2005;32:1253-1258.

30 Ohta M, Tokuda Y, Suzuki Y, Kubota M, Makuuchi H, Tajima T, Nasu S, Yasuda S, Shohtsu A: Whole body PET for the evaluation of bony metastases in patients with breast cancer: comparison with 99 Tcm-MDP bone scintigraphy. Nucl Med Commun 2001;22:875-879.

31 Yang SN, Liang JA, Lin FJ, Kao CH, Lin CC, Lee CC: Comparing whole body (18)F-2-deoxyglucose positron emission tomography and technetium- $99 \mathrm{~m}$ methylene diphosphonate bone scan to detect bone metastases in patients with breast cancer. J Cancer Res Clin Oncol 2002;128:325-328.

32 Du Y, Cullum I, Illidge TM, Ell PJ: Fusion of metabolic function and morphology: sequential [18F] fluorodeoxyglucose positron-emission tomography/ computed tomography studies yield new insights into the natural history of bone metastases in breast cancer. J Clin Oncol 2007. 